\title{
The impact of voluntary food fortification on micronutrient intakes and status in European countries: a review
}

\author{
Áine Hennessy*, Janette Walton and Albert Flynn \\ School of Food and Nutritional Sciences, University College Cork, Cork, Republic of Ireland
}

\begin{abstract}
This review aims to assess the efficacy and safety of voluntary fortification as an option to address the occurrence of inadequate micronutrient intakes in population subgroups in Europe. Although legislation is harmonised across the European Union, fortification practices and patterns of consumption of fortified foods vary considerably between countries. While the proportion of children consuming fortified foods is greater than adults, the proportion of dietary energy obtained from fortified foods is generally low $(<10 \%$ in Ireland, where fortified foods are widely consumed). There are a few systematic studies on the overall nutritional impact of voluntary fortification, but there are several studies on the impact of fortified ready-to-eat breakfast cereals. The available evidence indicates that voluntary fortification can reduce the risk of sub-optimal intakes of a range of micronutrients at a population level and can also improve status for selected micronutrients (e.g. folate, vitamin D and riboflavin) in children and adults. Although concerns have been raised regarding the potential of food fortification to lead to unacceptably high micronutrient intakes, particularly for those consuming higher amounts of fortified foods, data from national surveys on total micronutrient intakes (including fortified foods) in Europe show that small proportions of the population, particularly children, may exceed the upper intake level (UL) for some micronutrients. The risk of adverse effects occurring in these individuals exceeding the UL by modest amounts is low. In conclusion, voluntary fortification practices have been shown to improve intake and status of key micronutrients in European Union population groups and do not contribute appreciably to risk of adverse effects.
\end{abstract}

Fortification: Micronutrients: Vitamins: Minerals: Micronutrient adequacy

It has been well established that micronutrients play a pivotal role in achieving and maintaining optimum health across all life stages. Data from a number of national dietary surveys across Europe suggest a significant prevalence of inadequate intake and suboptimal status of some micronutrients in population subgroups, such as children, adolescents, young women and older adults $^{(1-10)}$. A recent paper by Mensink et al. ${ }^{(11)}$ evaluated the prevalence of low micronutrient intakes in adults and children using recent nationally representative dietary survey data from eight European countries. Reanalysis of raw data was conducted to obtain uniformity with respect to age-groups and method of assessing adequacy. A significant proportion of individuals had intakes below the estimated average requirement and lower reference nutrient intake for vitamin $\mathrm{D}$, iron, vitamin $\mathrm{A}$, iodine, magnesium and selenium in a number of population groups $^{(11)}$.

In Ireland, recent data on micronutrient intake and status from the Irish Universities Nutrition Alliance national nutrition surveys ${ }^{(10,12-16)}$ have indicated that inadequate micronutrient intakes occur in some population groups, particularly for iron, calcium, folate, vitamin $\mathrm{A}$ and vitamin $\mathrm{D}$. The latest findings from the National Diet and Nutrition Survey $(2008-2011)^{(3)}$ in the UK showed that dietary intakes of vitamin A, vitamin $\mathrm{D}$, riboflavin, magnesium and selenium were inadequate and suboptimal status was observed for iron and vitamin $\mathrm{D}$, and to a lesser extent for riboflavin in many subgroups of the UK population.

Abbreviations: MDI, mean daily intake; NANS, National Adult Nutrition Survey; NSIFCS, North/South Ireland Food Consumption Survey; RTEBC, ready-to-eat breakfast cereal; RTEC, ready-to-eat cereal; UL, upper intake level.

*Corresponding author: Á. Hennessy, fax +353 (0)21 427 0244, email a.hennessy@ucc.ie 
In light of these findings, it is important to consider methods for increasing the micronutrient intakes and nutritional status of population groups at risk of inadequate intakes. Improved nutrition education, nutritional supplement use and food fortification represent three options that have been put forward ${ }^{(17)}$. Nutritional supplement use has been effective in addressing inadequate micronutrient intake at an individual level ${ }^{(18)}$; however, uptake of use at the population level tends to be low $^{(19)}$. For example, folic acid supplement use in women of child-bearing age is generally low despite nutrition education programmes ${ }^{(10)}$. Thus, relying on nutritional supplement use has limitations as a public health strategy to increase micronutrient intakes at a population level. The voluntary addition of vitamins and minerals to appropriate foods represents one approach that has been shown to be an effective foodbased strategy to increase micronutrient intakes and reduce inadequacy at a population level ${ }^{(20)}$.

\section{Definition of voluntary fortification}

Voluntary fortification refers to the addition of vitamins or minerals to foods at the discretion of the manufacturer for a number of purposes: restoration, ensuring nutritional equivalence of substitute foods and enhancing the nutritive value of a food. Restoration refers to the replacement of nutrients that may be lost during manufacturing and processing of foods and during normal storage and handling, to the levels that were present prior to the manufacturing procedures. Foods that are produced for use as a partial or complete replacement of a food item may be fortified to ensure that the substitute food is of a similar nutritive value in terms of the quantity and bioavailability of the micronutrients. Foods may also be fortified to enhance their nutritive value, irrespective of whether the nutrient was originally present in the food ${ }^{(21)}$.

\section{Legislation}

Prior to 2006, the national regulations that governed the voluntary fortification of foods intended for general consumption in Europe varied widely. Countries such as Ireland and the UK permitted liberal voluntary fortification practices in which the addition of nutrients to foods was not restricted in terms of the types of food, nutrients or amounts that were added, provided it was not injurious to health and labelling did not mislead the consumer ${ }^{(22)}$. Voluntary fortification in these countries was governed by the general regulations of food safety ${ }^{(23)}$. Nordic countries such as Norway, Denmark, Finland and Sweden have traditionally been restrictive in their policies on voluntary fortification, viewing it as unnecessary and potentially harmful, requiring a documented public health need to justify fortification $^{(24)}$. Permission was required for voluntary fortification in countries such as Denmark and Italy, while tight controls on fortification with specific nutrients (fat-soluble vitamins and some minerals) existed in Germany, the Netherlands and Finland to a lesser extent ${ }^{(23)}$. These variations in policy were seen as a barrier to trade by the Food and Agriculture Organization ${ }^{(25)}$ and against the European Union free-trade philosophy ${ }^{(21)}$.

In 2006, the adoption of Regulation 1925/2006 of the European Parliament and of the Council on the addition of vitamins and minerals and certain other substances to foods ${ }^{(21)}$ resulted in a wide-ranging debate on the benefits and possible risks of voluntary fortification. This regulation set out to harmonise the legislation pertaining to the addition of micronutrients to food and to provide for free movement of goods within the European Union. This regulation also outlined a list of all substances that are permitted for fortification ${ }^{(26)}$, in order to take into account: (1) deficiency of one or more nutrients in a population or sub-population group that can be demonstrated by clinical or sub-clinical evidence of deficiency or indicated by estimated low levels of intake of nutrients; (2) potential for improving the nutritional status of a population and/or correct possible deficiencies in dietary intake due to changing dietary habits; and (3) evolving generally acceptable scientific knowledge on the role of micronutrients in nutrition and their consequent effects on health.

\section{Fortification practices and consumption in Europe}

Although regulation of voluntary food fortification is harmonised across the European Union, there are differences in fortification practices between countries. Some countries also have separate national policies on voluntary fortification, e.g. fortification of fluid milk products and margarines with vitamin $\mathrm{D}$ in Finland ${ }^{(27)}$. In response to very low intakes and poor status of vitamin $\mathrm{D}$ in the Finnish population, the Finnish Ministry of Trade and Industry launched a decree on optimal fortification of foods in 2003, encouraging the addition of vitamin $\mathrm{D}$ to fluid milk products $(0.5 \mu \mathrm{g} / 100 \mathrm{ml})$ and margarines and butter $(10 \mu \mathrm{g} / 100 \mathrm{~g})^{(27)}$.

In Ireland, national food consumption data of adults $^{(20)}$ show that ready-to-eat breakfast cereals (RTEBC), cereal bars, fat spreads, breads and juices and juice drinks are the main food groups that contribute to energy intake from fortified foods. In Irish adults aged 18-64 years, the proportion of participants consuming fortified foods increased from $67 \%$ in the North/South Ireland Food Consumption Survey (NSIFCS; $1997-1999)^{(20)}$ to $82 \%$ in the National Adult Nutrition Survey (NANS; 2008-2010) $)^{(28)}$ and the number of fortified foods recorded as consumed increased from 54 to 150 . The proportion of energy from fortified foods also increased from $4 \%$ in the NSIFCS to $9 \%$ in the NANS ${ }^{(28)}$. RTEBC are the most commonly consumed fortified foods by Irish adults and their contribution to energy intake has generally remained constant across the two surveys. The increase in energy from all fortified foods was partially attributable to fortification of some brands of bread with folic acid, primarily white breads. There is evidence to suggest that this practice of 
fortifying bread with folic acid in Ireland has declined significantly since the time of NANS data collection. The fortification of fat spreads with folic acid, vitamin $\mathrm{B}_{6}$ and vitamin $\mathrm{B}_{12}$ has also contributed to the increase in energy from fortified foods. The increase in the number of fortified foods in other food groups such as powdered beverages, isotonic and energy drinks and powdered soups and sauces has had a very minor effect on increasing energy intake from fortified foods.

Analysis of Irish food consumption data for school children (2003-2004), teenagers (2005-2006) and adults (2008-2010) has shown that fortified foods are consumed by a greater proportion of school children $(98 \%)$ than teenagers $(90 \%)$ and adults $(82 \%)$. This age-related decline of fortified food consumption has also been shown in other countries ${ }^{(5,9,29)}$. In Irish teenagers ${ }^{(30)}$ and school children ${ }^{(31)}$, RTEBC represent the main contributor to energy intake from fortified foods, followed by cereal bars and beverages.

In the UK, RTEBC, cereal bars, soft drinks (encompassing fruit juices and fruit juice drinks, squashes and sports drinks) and milks made up the largest proportion of fortified foods reported in a survey in 1999 by the Food Commission ${ }^{(32)}$.

Data from the Dutch National Food Consumption Survey $(2007-2010)^{(9)}$ of people aged 7-69 years indicate that the most frequently consumed fortified food products in the Netherlands are margarines, accounting for $28 \%$ of the fortified foods, dairy products $(12 \%)$, carbonated and cordial beverages $(11 \%)$ and fruit juices $(9 \%)$. In Finland, the use of voluntarily fortified foods among adults was investigated by Hirvonen et al. ${ }^{(33)}$ using data collected in the FINDIET Survey 2007. FINDIET 2007 used a 5-d barcode-based product diary in which a sub-sample of participants $(50 \%)$ were asked to record all food items that were purchased for home consumption by any member of the household or by the participant for their outside-the-home food consumption. The authors found that $2.6 \%$ of all foods purchased (by mass) were voluntarily fortified and the most common were yoghurts $(44 \%)$ followed by fruit drinks $(36 \%)$.

A report by Wagner et al. ${ }^{(34)}$ in 2005 collected details on the Austrian fortified food supply through a number of supermarket surveys and inspections over a period of 4 months. In total, 470 fortified foods were identified. Fortified baby foods were found to be the most common type of fortified food (29\%), followed by beverages $(21 \%)$, which were made up mainly of multivitamin or vitamin C-enriched products, energy drinks and isotonic sports drinks. Sweets (including biscuits, chocolates and marmalade) made up $17 \%$ of the fortified foods identified, whereas beverage powders (including instant teas, instant powders or chocolate powders) made up $11 \%$ of fortified foods.

The Dortmund Nutritional and Anthropometric Longitudinally Designed study in German children tracked the consumption of fortified foods, starting in 1985 with children and adolescents of different ages and followed them up to the age of 20 years (girls) and 23 years (boys). Sichert-Hellert et al. ${ }^{(35)}$ reported that energy intake from fortified foods increased from 6 to $9 \%$ between 1987 and 1996. Sichert-Hellert et al. ${ }^{(29)}$ reported that from 1986 to 1996 the most commonly fortified food products recorded were beverages $(30 \%)$, children's foods $(22 \%)$, cereals $(13 \%)$, fats/oils $(10 \%)$ and sweets/biscuits $(10 \%)$. Kersting et al. ${ }^{(36)}$ also conducted a market survey to characterise the German fortified food supply in 1994 and reported a total of 288 fortified foods available for consumption, predominantly made up of beverages (44\%), sweet foods $(20 \%)$, breakfast cereals $(18 \%)$ and dairy products $(12 \%)$. In the same year of the Dortmund Nutritional and Anthropometric Longitudinally Designed study, participants consumed 158 fortified food products with the same food group proportions, indicating that the Dortmund Nutritional and Anthropometric Longitudinally Designed study participants consumed a typical part of the fortified food supply available in Germany.

\section{Impact of food fortification on micronutrient intakes and status}

There are few nationally representative studies that examine the impact of food fortification on micronutrient intakes and status within Europe. Comprehensive data on the impact of food fortification on micronutrient intake are available for Ireland. In a paper by Hannon et al. ${ }^{(20)}$, the impact of food fortification was quantified using data from the NSIFCS (1997-1999) of adults aged 18-64 years. In consumers of fortified foods $(67 \%)$, the authors reported that relative to the percentage contribution of fortified foods to energy (men: 4\%; women: $5 \%$, fortified foods contributed a greater percentage to the mean daily intake (MDI) for iron (men: $16 \%$; women: $19 \%$ ), total folate (men: $18 \%$; women: $21 \%$ ), thiamin (men: 14\%; women: 16\%), riboflavin (men: $16 \%$; women: 18\%), vitamin $\mathrm{B}_{6}$ (men: $12 \%$; women: $15 \%$ ), vitamin $\mathrm{D}$ (men: $5 \%$; women: $11 \%$ ), vitamin $\mathrm{B}_{12}$ (men: $5 \%$; women: $7 \%$ ) and total niacin (men: $10 \%$; women: $12 \%$ ). This study also suggests that voluntary food fortification had a significant impact on reducing the proportion of the population with suboptimal intakes for many micronutrients, particularly iron (women: 49 to $31 \%$ ), folic acid (women: 12 to $3 \%$ ) and riboflavin (men: 16 to $7 \%$; women: 26 to $12 \%$ ). A more recent analysis of food fortification in Ireland from the NANS (2008-2010) $)^{(28)}$ has shown that relative to energy intake $(9 \%)$, fortified foods made a substantially greater contribution to intakes of a number of micronutrients, such as folate $(27 \%)$, vitamin $\mathrm{B}_{6}(22 \%)$, iron $(21 \%)$, vitamin D $(21 \%)$ and riboflavin $(19 \%)^{(28)}$.

Data collected in the National Children's Food Survey (2003-2004) of Irish children aged 5-12 years showed that relative to the contribution of fortified foods to MDI of energy $(9 \%)$, fortified foods made a substantial contribution in particular to MDI of iron $(33 \%)$, folate $(30 \%)$, vitamin $\mathrm{B}_{6}$ and thiamin $(28 \%)$, riboflavin $(26 \%)$, niacin $(21 \%)$, vitamin D and pantothenic acid $(15 \%)^{(37)}$. The authors also report that voluntary fortification of food significantly improved adequacy of intake of 
riboflavin, vitamin $\mathrm{B}_{6}$, folate and iron in children. Similarly in Irish teenagers (13-17 years), relative to their contribution to MDI of energy $(7 \%)$, fortified foods made a significant contribution to intakes of a number of micronutrients, such as folate $(25 \%)$, iron $(23 \%)$, thiamin, riboflavin and vitamin $\mathrm{B}_{6}(21 \%$ respectively), niacin $(14 \%)$ and vitamin D $(13 \%)^{(38)}$.

In the Netherlands, voluntary fortification was found to contribute significantly to intakes of $\mathrm{B}$ vitamins and vitamin $C$ in Dutch people aged 7-69 years $^{(9)}$. This may be reflective of the types of foods that are most commonly fortified in the Netherlands, for example, margarines, dairy products and juices. The added nutrient component of fortified foods accounted for $17 \%$ of total vitamin $\mathrm{B}_{6}$ intake, $10 \%$ of total riboflavin intake, $9 \%$ of total folate and total vitamin $\mathrm{C}$ intake and $8 \%$ to total intake of thiamin.

In Germany, the Dortmund Nutritional and Anthropometric Longitudinally Designed study reported on the contribution of fortified foods to nutrient intakes of children aged 2-14 years, over a 10-year period $(1987-1996)^{(35)}$. Over time, the consumption of fortified foods was found to increase as indicated by the observed increase in percentage energy from fortified foods $(6-9 \%)$ and as expected, the contribution of fortified foods to total intakes of vitamins and minerals was also found to increase significantly over time. Sichert-Hellert et al. $^{(35)}$ assessed the efficacy of food fortification in raising micronutrient intakes (as $\%$ of the German reference intake values). The authors reported that food fortification was effective in raising low intakes of vitamin $\mathrm{E}$ and folate from $50 \%$ of reference intake values to $80 \%$ (folate) and $100 \%$ (vitamin $\mathrm{E}$ ) of reference values. Food fortification increased already sufficient intakes of vitamins $\mathrm{A}, \mathrm{C}$, thiamin, riboflavin, niacin and vitamin $\mathrm{B}_{6}$.

The effect of voluntary fortification on the status of folate and related B vitamins in Northern Ireland was investigated by Hoey et al. ${ }^{(39)}$ between 2003 and 2005 using a convenience sample of 662 adults (18-92 years). This study found that over three-quarters of participants consumed foods fortified with folic acid alone or in combination with other B vitamins more than once per week. The most commonly consumed folate and B vitamin fortified foods were RTEBC (63\% consumers), followed by fat spreads $(25 \%$ consumers $)$. The authors found significant increases in dietary intakes of total folate, vitamin $B_{12}$, vitamin $B_{6}$ and riboflavin with increasing consumption of fortified foods, which in turn were reflected in enhanced biomarker status of these vitamins. More specifically, Hoey et al. ${ }^{(39)}$ found a significant graded increase in folic acid intake and red cell folate and serum folate status, with increasing level of fortified food consumption. Similar findings on folate status of the Irish adult population (18-90 years) from the NANS (2008-2010) were reported by Hopkins et al. ${ }^{(15)}$ where folic acid consumers (from fortified foods) had significantly better folate status (red cell folate and serum folate) than non-consumers of folic acid.

Hoey et al. ${ }^{(39)}$ examined red cell folate status separately in women of child-bearing age. The authors found that the proportion of women with favourable red cell folate status with respect to preventing neural tube defects increased significantly with increasing fortified food intake. Participants in the top tertile of fortified food intake were found to have median folic acid intake of $208 \mu \mathrm{g} / \mathrm{d}$. This value is comparable with the estimated increase of $190 \mu \mathrm{g} / \mathrm{d}$ folic acid as a result of mandatory fortification in the $\mathrm{USA}^{(40)}$. There is evidence to suggest that this level of intake is effective in improving folate status to prevent neural tube defects ${ }^{(41)}$. The findings of this study suggest that voluntary fortification may be effective in reducing neural tube defect risk in women who regularly consume fortified foods.

In Finland, Laaksi et al. ${ }^{(42)}$ evaluated the impact of the vitamin D optimisation policy through the collection of serum samples from a total of 196 young Finnish male conscripts (18-28 years) in January 2003 (before the policy was implemented) and in January 2004, almost 1 year after national vitamin $\mathrm{D}$ fortification had started. The authors report that after fortification, the young men were ingesting on average $7 \mu \mathrm{g}$ vitamin $\mathrm{D}$ daily from fluid milk products and margarine alone. The authors found that the mean serum 25-hydroxyvitamin $\mathrm{D}_{3}$ concentrations during wintertime increased by $50 \%$ and the prevalence of vitamin $\mathrm{D}$ insufficiency (serum 25-hydroxyvitamin $\mathrm{D}_{3}<40 \mathrm{nmol} / 1$ ) decreased from $78 \%$ in January 2003 to $35 \%$ in January 2004. Vitamin D deficiency (serum 25-hydroxyvitamin $\mathrm{D}_{3}<25 \mathrm{nmol} / \mathrm{l}$ ) decreased from 19 to $5 \%$ since the implementation of the vitamin $\mathrm{D}$ fortification policy.

\section{Impact of ready-to-eat breakfast cereals on micronutrient intakes and status}

There are many studies on the beneficial impact of RTEBC on micronutrient intakes and status in a number of European countries ${ }^{(43-49)}$. Data from Ireland have consistently shown over time that RTEBC make a significant contribution to micronutrient intakes. Sommerville and O' Reagan ${ }^{(50)}$, using data from the Irish National Nutrition Survey ${ }^{(51)}$ of people aged 8-80 years in 1990, found that breakfast cereal consumers had significantly higher intakes of $\mathrm{B}$ vitamins, calcium and iron than non-consumers. Galvin et al. ${ }^{(4)}$ found that RTEBC consumption by Irish adults aged 18-64 years $(60 \%$ of males and $63 \%$ of females) in the NSIFCS (1997-1999) contributed substantially to MDI of iron $(18 \%)$, total folate $(18 \%)$, riboflavin $(17 \%)$, niacin $(16 \%)$, thiamin $(14 \%)$, vitamin $\mathrm{B}_{6}(13 \%)$ and vitamin $\mathrm{D}$ $(10 \%)$. Increased consumption of fortified RTEBC had a significant impact on improving adequacy of intake for a number of micronutrients, particularly calcium, copper, zinc, riboflavin and vitamin $\mathrm{C}$ in men and women and iron and total folate in women ${ }^{(43)}$.

Hannon and Flynn ${ }^{(52)}$ reported that the majority of Irish schoolchildren in the National Children's Food Survey (2003-2004) were consumers of RTEBC $(95 \%$ of boys and $91 \%$ of girls). The authors reported that RTEBC contributed significantly to intakes of iron $(30 \%)$, folate $(24 \%)$ and $\mathrm{B}$ vitamins $(17-24 \%)$. Walsh 
et $a{ }^{(53)}$ reported that $81 \%$ of Irish teenagers in the National Teens' Food Survey (2005-2006) were consumers of RTEBC and that RTEBC contributed significantly to intakes of $\mathrm{B}$ vitamins and iron (13-26\%).

In the UK, Gibson and Gunn ${ }^{(54)}$ found that consumption of breakfast cereal by adults aged 19-64 years in the National Diet and Nutrition Survey (2000-2001) resulted in substantially higher micronutrient intakes (30-90\%) than when a non-cereal breakfast was consumed. Given that the difference in energy intake between groups was relatively smaller, these findings indicate that there is a strong positive effect on nutrient density on breakfast cereal consumption days in particular. This increase in micronutrient intake and density may be largely attributable to the fortification element of breakfast cereals. McNulty et al. ${ }^{(55)}$ have previously shown that fortification of breakfast cereals made a significant contribution to micronutrient intakes in British adults from the Diet and Nutrition Survey of British Adults (1986-1987) for each of the nutrients studied.

Gibson $^{(44)}$ found that British children aged 4-18 years in the National Diet and Nutrition Survey (1997), increasing consumption of breakfast cereals was positively associated with greater intakes of iron, folate, vitamin $\mathrm{D}$, calcium, $\mathrm{B}$ vitamins and zinc, in addition to more favourable folate status, vitamin $B_{12}$ status and riboflavin status in boys and girls, and thiamin status and vitamin $\mathrm{B}_{6}$ status in girls only. Gibson found a significant association between level of fortified RTEBC consumption and the reduced prevalence of inadequate intakes in girls of iron, riboflavin, calcium and potassium. However, there was no evidence of an association of breakfast cereal consumption and enhanced iron status or reduced prevalence of poor iron status. Gibson ${ }^{(47)}$ also observed this disparity between iron intake and status in breakfast cereal consumers aged $1.5-4.5$ years in the National Diet and Nutrition Survey (1992-1993). It has been suggested that reasons for the poor correlation of estimated dietary intake of iron with iron status may be due to the variability in iron absorption in different individuals based on their current iron stores, differing bioavailability due to the form of iron that is present in foods and the presence of iron absorption inhibitors or enhancers in the $\operatorname{diet}^{(56)}$. McNulty et al. ${ }^{(57)}$ found that in Northern Irish school children (12-15 years old), the intakes of a number of micronutrients, such as folate, iron, calcium and B vitamins, increased significantly with increasing consumption of fortified breakfast cereals, as well as adequacy of micronutrient intake.

In Spain, the contribution of ready-to-eat cereals (RTEC) to micronutrient intakes was investigated in the enKid Study (1998-2000) of Spanish children, adolescents and young adults (2-24 years) ${ }^{(46)}$. Intakes of thiamin, riboflavin, vitamin $\mathrm{B}_{6}$, niacin, folate, calcium, iron and vitamin $\mathrm{D}$ increased significantly with increasing level of RTEC consumption and there was a significant association between the level of RTEC consumption and an improved likelihood of meeting daily nutrient requirements for calcium, iron, thiamin, riboflavin, niacin, vitamin $\mathrm{B}_{6}$, folate and vitamin D, some of which are not traditionally added to
RTEC. In an earlier study into fortified breakfast cereal consumption in Spanish schoolchildren, Ortega et al. ${ }^{(48)}$ found that consumers of fortified breakfast cereals had significantly higher intakes of thiamin, vitamin $\mathrm{B}_{6}$, folate and carotene than non-consumers. In addition, a positive association of fortified breakfast cereal consumption with more favourable status of folate, retinol and riboflavin was found in Spanish school children.

Preziosi et al. ${ }^{(45)}$ provided evidence for the positive impact of breakfast cereals on the nutrient intakes and status of French children, adolescents and adults. Intakes and dietary nutrient density of a range of micronutrients in children and adults was positively associated with consumption of RTEC. In children, higher dietary intakes of calcium, phosphorous, iron, thiamin and riboflavin were observed in consumers than nonconsumers, whereas in adults consumers had higher intakes of calcium and phosphorous, thiamin and riboflavin, vitamins $\mathrm{A}$ and $\mathrm{C}$ and folic acid than nonconsumers of RTEC. Children and adolescent consumers of RTEC had significantly higher serum riboflavin and $\beta$-carotene concentrations than non-consumers. The authors also report that adult consumers of RTEC had significantly higher status of thiamin and riboflavin and higher serum levels of folate and $\beta$-carotene than non-consumers.

\section{Risk of excessive micronutrient intakes}

The potential for voluntary food fortification to lead to unacceptably high intakes of micronutrients has been considered, particularly for those consuming large amounts of fortified foods. Although the European Union legislation provides for the setting of maximum safe levels of vitamins and minerals in fortified foods, this has not yet been implemented. Several models for estimating the safe levels of addition of micronutrients to foods have been proposed ${ }^{(58-60)}$. Some countries (Belgium, Denmark, the Netherlands and the UK) have placed restrictions on the level of folic acid that can be added to food and approval is required before a folic acid-fortified food can be marketed in Norway and Denmark ${ }^{(61)}$

In general, total micronutrient intakes (including fortified foods and nutritional supplements) of high consumers (as defined by the 95th percentile of intake) in adults and children across Europe do not exceed the tolerable upper intake levels (UL) set by the European Food Safety Authority ${ }^{(23)}$. Flynn et al. ${ }^{(23)}$ evaluated intakes of micronutrients derived from nine nationally representative surveys in Europe and found for most nutrients, adults and children generally consume considerably less than the UL. For some micronutrients (retinol, zinc, iodine, copper and magnesium) small proportions of the population, particularly children, exceeded the UL. However, the authors concluded that there is little risk of adverse effects occurring in the small proportion of individuals exceeding the UL by a modest amount given the use of adequate safety factors in establishing UL. 
The impact of the added nutrient component of fortified foods has been investigated in a number of studies. In Ireland, Hannon et al. ${ }^{(20)}$ reported that 95th percentile intakes of Irish adults from the NSIFCS (1997-1999) did not exceed or approach the UL for any micronutrient, with or without the added nutrient from fortification included in the estimate of intakes. While a small proportion of fortified food consumers $(<2 \%)$ had intakes which exceeded the UL (for vitamin $\mathrm{B}_{6}$, folic acid, zinc and retinol), this was not driven by fortification, but rather by nutritional supplement use for folic acid, vitamin $\mathrm{B}_{6}$ and zinc and from the base diet for retinol ${ }^{(20)}$. Preliminary analysis of more recent data from the NANS (2008-2010) in Ireland indicates that this situation has not changed.

Hannon $^{(31)}$ identified small proportions $(<4 \%)$ of Irish children in the National Children's Food Survey (2003-2004) with total intakes of retinol, vitamin $\mathrm{B}_{6}$, folic acid, zinc and copper above the UL. Similarly in teenagers, Walsh ${ }^{(30)}$ using data from the National Teens' Food Survey (2005-2006) identified small proportions $(<4 \%)$ of Irish teenagers with total intakes of retinol, vitamin $\mathrm{B}_{6}$, folic acid and iodine above the UL. However, the voluntary fortification of foods did not contribute appreciably to increased risk of excessive intake for any of these nutrients.

In Finland, the introduction of the vitamin D optimisation policy resulted in a small increase in the proportion of young Finnish men with serum 25-hydroxyvitamin $\mathrm{D}_{3}$ concentration higher than $100 \mathrm{nmol} / 1$, from $0 \%$ before the policy was introduced to $5 \%$ after fortification; however no clinical signs of toxicity were observed at this concentration $^{(42)}$.

\section{Conclusion}

Although the proportion of children consuming fortified foods is greater than adults, the proportion of dietary energy obtained from fortified foods is generally low $(<10 \%$ of energy intake for children, teenagers and adults in Ireland), where fortified foods are widely consumed. There are a few systematic studies on the overall nutritional impact of voluntary fortification but there are several studies on the impact of fortified RTEBC. The available evidence indicates that voluntary fortification can reduce the risk of sub-optimal intakes of range of micronutrients at a population level. There is also evidence that voluntary fortification can improve status for selected micronutrients (e.g. folate, vitamin $\mathrm{D}$, riboflavin) in children and adults. Concerns have been raised regarding the potential of food fortification to lead to unacceptably high intakes of micronutrients, particularly for those consuming higher amounts of fortified foods. Data from national surveys on total intakes of micronutrients (including fortified foods) in Europe show that small proportions of the population, particularly children, may exceed the UL for some micronutrients. However, there is little risk of adverse effects occurring in the small proportion of individuals exceeding the UL by a modest amount. Current fortification practices do not appear contribute appreciably to this risk.

\section{Acknowledgements}

None.

\section{Financial Support}

This work was supported by funding from the Irish Department of Agriculture, Food and the Marine under the Food for Health Research Initiative (20072012). The Irish Department of Agriculture, Food and the Marine had no role in the design, analysis or writing of this article.

\section{Conflicts of Interest}

None.

\section{Authorship}

A. H. wrote the review, J. W. and A. F. provided expert advice in the drafting of the paper and were responsible for critically reviewing and approving the final version of the manuscript.

\section{References}

1. Hannon E, Kiely M, Harrington K et al. (2001) The North/ South Ireland Food Consumption Survey: mineral intakes in 18-64-year-old adults. Public Health Nutr 4, 1081-1088.

2. Manios Y, Grammatikaki E, Papoutsou S et al. (2008) Nutrient intakes of toddlers and preschoolers in Greece: the GENESIS study. $J$ Am Diet Assoc 108, 357-361.

3. Bates B, Lennox A, Prentice A et al. (2012) National Diet and Nutrition Survey. Headline results from Years 1, 2 and 3 (combined) of the Rolling Programme (2008/ 2009-2010/2011). Food Standards Agency and the Department of Health. Available at: http://www.natcen. ac.uk/media/978078/ndns-y3-report_all-text-docs-combined. pdf (accessed April 2013).

4. O'Brien M, Kiely M, Harrington K et al. (2001) The North/South Ireland Food Consumption Survey: vitamin intakes in 18-64-year-old adults. Public Health Nutr 4, 1069-1079.

5. Ocké MC, van Rossum CTM, Fransen HP et al. (2008) Dutch National Food Consumption Survey - Young Children 2005/2006. National Institute for Public Health and the Environment. Available at: http://www.rivm.nl/ bibliotheek/rapporten/350070001.pdf (accessed April 2013).

6. Paturi M, Tapanainen H, Reinivuo $\mathrm{H}$ et al. (2008) The National FINDIET 2007 Survey. Helsinki: National Public Health Institute.

7. Serra-Majem L, Ribas-Barba L, Pérez-Rodrigo C et al. (2006) Nutrient adequacy in Spanish children and adolescents. Br J Nutr 96, S49-S57.

8. Serra-Majem L, Ribas-Barba L, Salvador G et al. (2007) Trends in energy and nutrient intake and risk of inadequate intakes in Catalonia, Spain (1992-2003). Public Health Nutr 10, 1354-1367. 
9. van Rossum CT, Fransen HP, Verkaik-Kloosterman J et al. (2011) Dutch National Food Consumption Survey 2007-2010: Diet of children and Adults Aged 7 to 69 Years. www.rivm.nl/vep/.

10. Walsh E, Walton J, McNulty B et al. (2011) Intakes of micronutrients in Irish adults (18-64 years). Proc Nutr Soc 70, E114.

11. Mensink GBM, Fletcher R, Gurinovic M et al. (2013) Mapping low intake of micronutrients across Europe. Br J Nutr FirstView, 1-19.

12. Cashman KD, Muldowney S, McNulty B et al. (2013) Vitamin D status of Irish adults: findings from the National Adult Nutrition Survey. Br J Nutr 109, 1248-1256.

13. Hannon EM, Kiely M \& Flynn A (2005) Adequacy of micronutrient intakes in Irish children aged 5 to 12 years. Ann Nutr Metab 49, 256.

14. Hayes E, Walton J, Hannon EM et al. (2008) Micronutrient intake in Irish teenagers (13-17 years). Proc Nutr Soc 67, E275.

15. Hopkins SM, McNulty BA, Walton J et al. (2012) Impact of voluntary fortification and supplement use on dietary intakes of folate and status in an Irish adult population. Proc Nutr Soc 71, E38.

16. Irish Universities Nutrition Alliance (2012) National Pre-School Nutrition Survey. Summary Report on: Food and Nutrient Intakes, Physical Measurements and Barriers to Healthy Eating. Dublin: IUNA.

17. Serra-Majem L (2001) Vitamin and mineral intakes in European children. Is food fortification needed? Public Health Nutr 4, 101-107.

18. Murphy SP, White KK, Park SY et al. (2007) Multivitamin-multimineral supplements' effect on total nutrient intake. Am J Clin Nutr 85, 280S-284S.

19. Browne F, Walsh E, Walton J et al. (2011) The contribution of nutritional supplements to micronutrient intake in Irish adults aged 18-64 years. Proc Nutr Soc 70, E111.

20. Hannon EM, Kiely M \& Flynn A (2007) The impact of voluntary fortification of foods on micronutrient intakes in Irish adults. Br $J$ Nutr 97, 1177-1186.

21. EC (2006) Regulation (EC) No 1925/2006 of the European Parliament and of the Council of 20 December 2006. Official J Eur Union L404/26, 26-38.

22. Scientific Co-operation Task 7.1.1. Working Group (1997) Scientific Considerations for the Development of Measures on the Addition of Vitamins and Minerals to Foodstuffs. Luxembourg: Office for Official Publications of the European Communities.

23. Flynn A, Hirvonen T, Mensink GBM et al. (2009) Intake of selected nutrients from foods, from fortification and from supplements in various European countries. Food Nutr Res 53, S1-S28.

24. Meltzer HM, Aro A, Andersen NL et al. (2003) Risk analysis applied to food fortification. Public Health Nutr 6, 281-291.

25. Food and Agriculture Organization (1996) Food Fortification: Technology and Quality Control. Rome, Italy: FAO.

26. EC (2009) Commission Regulation (EC) No 1170/2009 of 30 November 2009 amending Directive 2002/46/EC of the European Parliament and of Council and Regulation (EC) No 1925/2006 of the European Parliament and of the Council as regards the lists of vitamin and minerals and their forms that can be added to foods, including food supplements. Official J Eur Union L314, 36-42.

27. Pietinen P, Männistö S, Valsta LM et al. (2010) Nutrition policy in Finland. Public Health Nutr 13, 901-906.
28. Hennessy A, Walsh E, Walton J et al. (2011) The contribution of fortified foods to micronutrient intake in Irish adults aged 18-64 years. Proc Nutr Soc 70, E112.

29. Sichert-Hellert W, Kersting M \& Schoch G (1999) Consumption of fortified food between 1985 and 1996 in 2- to 14-year-old German children and adolescents. Int J Food Sci Nutr 50, 65-72.

30. Walsh E (2011) Role of fortified foods and nutritional supplements in the diets of Irish children and teenagers. PhD Thesis, Cork: University College Cork.

31. Hannon EM (2006) The National Children's Food Survey: Micronutrient intakes and risk-benefit analysis of micronutrient fortification of foods in Irish children. PhD Thesis, Cork: University College Cork.

32. Bonner G, Warwick H, Barnardo M et al. (1999) Fortification Examined: How Added Nutrients can Undermine Good Nutrition. London: The Food Commission.

33. Hirvonen T, Kara A, Korkalo L et al. (2012) Use of voluntarily fortified foods among adults in Finland. Public Health Nutr 15, 802-810.

34. Wagner KH, Blauensteiner D, Schmid I et al. (2005) The role of fortified foods - situation in Austria. Forum Nutr 57, 84-90.

35. Sichert-Hellert W, Kersting M, Alexy U et al. (2000) Ten-year trends in vitamin and mineral intake from fortified food in German children and adolescents. Eur $J$ Clin Nutr 54, 81-86.

36. Kersting M, Hansen C \& Schoch G (1995) Survey of the present day supply of fortified food products in Germany. $Z$ Ernährungswiss 34, 253-260.

37. Hannon EM, Kiely M \& Flynn A (2006) Contribution of fortified foods to nutrient intakes in Irish children aged 5 to 12 years. Proc Nutr Soc 65, 34A.

38. Walsh E, Walton J, Hayes E et al. (2010) Contribution of fortified foods to nutrient intakes in Irish teenagers aged 13 to 17 years. Proc Nutr Soc 69, E384.

39. Hoey L, McNulty H, Askin N et al. (2007) Effect of a voluntary food fortification policy on folate, related $\mathrm{B}$ vitamin status, and homocysteine in healthy adults. $\mathrm{Am}$ $J$ Clin Nutr 86, 1405-1413.

40. Choumenkovitch SF, Selhub J, Wilson PW et al. (2002) Folic acid intake from fortification in United States exceeds predictions. J Nutr 132, 2792-2798.

41. Daly S, Mills JL, Molloy AM et al. (1997) Minimum effective dose of folic acid for food fortification to prevent neural-tube defects. Lancet 350, 1666-1669.

42. Laaksi IT, Ruohola JP, Ylikomi TJ et al. (2006) Vitamin D fortification as public health policy: significant improvement in vitamin D status in young Finnish men. Eur J Clin Nutr 60, 1035-1038.

43. Galvin MA, Kiely M \& Flynn A (2003) Impact of ready-to-eat breakfast cereal (RTEBC) consumption on adequacy of micronutrient intakes and compliance with dietary recommendations in Irish adults. Public Health Nutr 6, 351-363.

44. Gibson S (2003) Micronutrient intakes, micronutrient status and lipid profiles among young people consuming different amounts of breakfast cereals: further analysis of data from the National Diet and Nutrition Survey of Young People aged 4 to 18 years. Public Health Nutr 6, $815-820$

45. Preziosi P, Galan P, Deheeger M et al. (1999) Breakfast type, daily nutrient intakes and Vitamin and mineral status of French children, adolescents and adults. J Am Coll Nutr 18, 171-178.

46. van den Boom A, Serra-Majem L, Ribas L et al. (2006) The contribution of ready-to-eat cereals to daily nutrient 
intake and breakfast quality in a Mediterranean setting. J Am Coll Nutr 25, 135-143.

47. Gibson SA (1999) Iron intake and iron status of preschool children: associations with breakfast cereals, vitamin $\mathrm{C}$ and meat. Public Health Nutr 2, 521-528.

48. Ortega RM, Requejo AM, Redondo R et al. (1996) Influence of the intake of fortified breakfast cereals on dietary habits and nutritional status of Spanish schoolchildren. Ann Nutr Metab 40, 146-156.

49. Sichert-Hellert W \& Kersting M (2003) Impact of fortified breakfast cereals on iron intake in German children and adolescents. J Pediatr Gastroenterol Nutr 36, 149-153.

50. Sommerville J \& O' Reagan M (1993) The contribution of breakfast to micronutrient adequacy of the Irish diet. J Hum Nutr Diet 6, 223-228.

51. Lee P \& Cunnigham K (1990) Irish National Nutrition Survey. Dublin: Irish Nutrition and Dietetic Institute.

52. Hannon EM \& Flynn A (2007) Contribution of ready-to-eat breakfast cereals to nutrient intakes in Irish children aged 5-12 years. Proc Nutr Soc 66, 43A.

53. Walsh E, Hannon EM, Walton J et al. (2011) Contribution of ready-to-eat breakfast cereals to nutrient intakes in Irish teenagers aged 13-17 years. Ann Nutr Metab 58, 221-222.
54. Gibson SA \& Gunn P (2011) What's for breakfast? Nutritional implications of breakfast habits: insights from the NDNS dietary records. Nutr Bull 36, 78-86.

55. McNulty H, Eaton-Evans J, Woulahan G et al. (1994) The effect of fortification on daily micronutrient intakes of breakfast cereal consumers in Great Britain. Proc Nutr Soc 53, 143A.

56. Hallberg L (1982) Iron absorption and iron deficiency. Hum Nutr Clin Nutr 36C, 259-278.

57. McNulty H, Eaton-Evans J, Cran G et al. (1996) Nutrient intakes and impact of fortified breakfast cereals in schoolchildren. Arch Dis Child 75, 474 481.

58. Flynn A, Moreiras O, Stehle P et al. (2003) Vitamins and minerals: a model for safe addition to foods. Eur $J$ Nutr 42, 118-130.

59. Kloosterman J, Fransen HP, de Stoppelaar J et al. (2007) Safe addition of vitamins and minerals to foods: setting maximum levels for fortification in the Netherlands. Eur J Nutr 46, 220-229.

60. Rasmussen S, Andersen N, Dragsted L et al. (2005) A safe strategy for addition of vitamins and minerals to foods. Eur $J$ Nutr 45, 123-135.

61. EFSA (2009) ESCO report prepared by the EFSA Scientific Cooperation Working Group on Analysis of Risks and Benefits of Fortification of Food with Folic Acid. EFSA. 